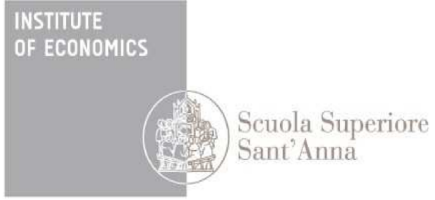

LEM | Laboratory of Economics and Management

Institute of Economics

Scuola Superiore Sant'Anna

Piazza Martiri della Libertà, 33 - 56127 Pisa, Italy ph. +3905088.33 .43$

institute.economics@sssup.it

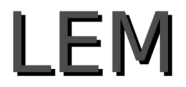

Working Paper Series

\title{
Global Trade Imbalances: A Network Approach
}

Marco Dueñas *

Giorgio Fagiolo *

'Institute of Economics and LEM, Scuola Superiore Sant'Anna, Pisa, Italy 


\title{
Global Trade Imbalances: A Network Approach*
}

\author{
Marco Dueñas ${ }^{\dagger} \quad$ Giorgio Fagiolo ${ }^{\ddagger}$
}

May, 2013

\begin{abstract}
We study trade imbalances between world countries in the period 1960-2000 using a complex-network approach. We show that trade imbalances in absolute value are characterized by a hierarchical arrangement wherein few rich economies display high clustering and carry an important amount of global-trade imbalances. In contrast, trade imbalances in relative terms show a more fragmented topology, with less concentrated clustering which is particularly high for emergent economies. In addition, we find that traditional null random-network models and the gravity model poorly predict the topology of trade imbalance networks. Our main finding is that the evolution of the international trade has caused very heterogeneous imbalances in world economies, which may have important consequences for global instability and development.
\end{abstract}

Keywords: Trade Imbalances; International Trade Network; Gravity Model; Null Models.

JEL codes: F10, D85.

\section{Introduction}

Trade imbalances are one of the main concerns for trade policy makers because they represent a source of friction between countries (Krugman and Baldwin, 1987; Hufbauer et al., 2006). International trade relations involve complex elements and asymmetries that often are mirrored in bilateral trade imbalances, affecting countries' external positions, and consequently leading to distortions and potential increase in protectionist pressures (Bracke et al.,

${ }^{*}$ The Authors gratefully acknowledge financial support received by the research project "The international trade network: empirical analyses and theoretical models" (www.tradenetworks.it) funded by the Italian Ministry of Education, University and Research (Scientific Research Programs of National Relevance 2009).

${ }^{\dagger}$ Corresponding author. Institute of Economics, Sant'Anna School of Advanced Studies, Pisa, Italy. Mail Address: Sant'Anna School of Advanced Studies, Piazza Martiri de la Libertà 33, 56127 Pisa, Italy. E-mail: m.duenasesterling@sssup.it.

${ }^{\ddagger}$ Institute of Economics, Sant’Anna School of Advanced Studies, Pisa, Italy. Mail Address: Sant’Anna School of Advanced Studies, Piazza Martiri de la Libertà 33, 56127 Pisa, Italy. Ted: +39-050-883359. Fax: +39-050-883359. E-mail: giorgio.fagiolo@sssup.it. 
2008). ${ }^{1}$ How to reduce trade imbalances is still a matter of debate for trade policy makers trying to rule the governance of the world trade system (Mattoo and Subramanian, 2008). Despite efforts, even-trade is difficult to promote, possibly because country asymmetries are undervalued (Subramanian and Wei, 2007). The message is that opening to trade affects countries differently, standard policies would work hardly for all in the same way, and international integration in trade might be far from being fully accomplished, caused by the strong heterogeneity in the profiles of cross-country trade partnerships (De Benedictis and Tajoli, 2011).

Trade imbalances are also connected with economic crisis and instability: the fact that big imbalances imply huge capital flows may lead to instabilities in importing countries. Given its connection with the current account, trade balance surplus is commonly associated with high investing and saving country profiles. For instance, it is expected that low-income countries with high rates of return to investment might borrow from abroad to finance their development (Krugman et al., 2011). But recently, developments in international capital markets have allowed investments in any country (not only locally), then if country's savings were higher than investment this excess might be lent on international capital markets, therefore causing a "saving glut" (Bernanke, 2005).

The most significant empirical fact is that trade imbalances are persistent (Gagnon and Rose, 1995) and difficult to explain (Davis and Weinstein, 2002). It is worth mentioning that recently most of the interest in imbalances has been largely on the U.S. and China, which in fact represents one of the most structural unbalanced bilateral relations of the contemporary international trade network (Serrano et al., 2007). But, also recently there have been other patterns of trade imbalances among developing and developed countries. ${ }^{2}$ This evidence calls for new approaches to comprehend the complexities of global imbalances as a network object, and not as isolated cases of study. Complex network analysis came into use in economics because they offer an elegant setup to understand interdependences (Schweitzer et al., 2009).

To better comprehend global trade imbalances, we provide the analysis of three different networks: i) the Total Trade Network (TTN), where links describe the value of imports plus exports between any two countries; ii) the Trade Imbalance Network (TIN), where links describe the absolute value of exports minus imports between any two countries; and, iii) the Relative Trade Imbalance Network (RTIN), where links describe the absolute value of exports minus imports divided by the total trade between any two countries. In this way, we abandon the traditional view focused on the overall trade imbalance of a single country and we pay more attention to the whole system of bilateral imbalances among trading partners. This

\footnotetext{
${ }^{1}$ Distortions might be driven by exaggerated or inappropriate policy interventions in financial markets, exchange rates, and/or taxes.

${ }^{2}$ Some East Asian nations, oil exporting countries, and few Latin American countries have had large and rising trade surpluses while several other high-income countries, such as Greece, Spain and the UK, have been running large and growing trade deficits (Bracke et al., 2008; Marchetti et al., 2012).
} 
approach allows a better understanding of the roles of developing countries that are catching up and least developed economies on global imbalances, and at the same time, inquiring for consequences that the own network-configuration impose on them.

The topological properties of the TTN have been already widely studied (Serrano and Boguñá, 2003; Garlaschelli and Loffredo, 2005; Fagiolo et al., 2010). It has been shown that the TTN exhibits a disassortative pattern: countries with many trade partners are on average connected with countries with few partners. Furthermore, partners of well connected countries are less interconnected than those of poorly connected ones -implying some hierarchical arrangements- and the number of trade partners by country appears to be very skewed, suggesting the coexistence of few countries with many partners and many countries with only a few partners. We show that the TIN and TTN have very similar architectures: the TIN is also disassortative with a very hierarchical structure, where countries that trade more are more unbalanced and central, and have neighbors with lower total trade and, for this reason, less unbalanced. Conversely, the RTIN topology has remarkable differences with respect to the TIN. Even if the RTIN is still disassortative, its clustering is not concentrated in few countries. In the RTIN, developing economies have higher clustering and there is no strong hierarchy. This shows that while rich economies are more unbalanced in absolute terms, because of their higher trade volumes, they also have less relative unbalanced relations. Another remarkable result is that many catching up economies are highly unbalanced in relative terms; in average many of them have completely asymmetric trade relations (just exporting or importing) with around a half of countries in sample. Considering the disassortativity of the networks, this highlights the role of those countries as drivers of international trade.

Additionally, we investigate whether the topological structure of our trade imbalance networks can be explained by simple statistical and econometric models. First, we test null random-network models, which belong to pure statistical techniques (Molloy and Reed, 1995; Maslov and Sneppen, 2002; Chung and Lu, 2002; Newman, 2003). And second, we fit trade flows by the traditional gravity model, covering a wide range of econometric techniques. We conclude that no model provides completely satisfactory results, nonetheless, null models provide marginally better predictions. In synthesis, the inability to predict correctly trade imbalances is because models and available data hardly capture the underlying complexity of the system. Our results agree with Serrano et al. (2007), which shows that heterogeneity in international trade is not exclusive of countries, but it is also observed in trade linkages.

The rest of the paper is organized as follows. In Sec. 2, we present data, network definitions, and node statistics. In Sec. 3, we analyze the topological aspects of our networks, and presents all the results in a dynamical fashion following different cross-sections. In Sec. 4, we ask for theoretical explanations for our observations. Finally, we conclude in Sec. 5. 


\section{Data and Definitions}

We use international trade data taken from Subramanian and Wei (2007), which contains aggregate bilateral imports reported by the IMF Direction of Trade Statistics, measured in U.S. dollars and deflated by U.S. Consumer Price Index at 1982-83 prices. We build 9 balanced cross-sections with 98 countries for the years 1960 to 2000, with a five-year lag. For the list of countries see Appendix A.

\subsection{Link Weights}

Let $W_{i j}(t)$ be the trade flow where $i$ is the exporter and $j$ the importer in year $t$. We focus on two measures of trade link imbalances, the absolute trade imbalance,

$$
T I_{i j}(t)=\left|W_{i j}(t)-W_{j i}(t)\right|
$$

and the absolute relative trade imbalance,

$$
R T I_{i j}(t)=\frac{\left|W_{i j}(t)-W_{j i}(t)\right|}{W_{i j}(t)+W_{j i}(t)}
$$

Clearly, both link-weight measures differ in scale and units; TI is measured in U.S. thousand dollars and RTI has no unit and its support is in [0,1]. Equations (1) and (2) are measures of bilateral trade imbalances but with different economic interpretations: $T I$ accounts for the amount of the unbalanced trade transactions in U.S. dollars; and, RTI accounts for the amount of trade asymmetries independently of the traded volume, i.e. it is a measure how reciprocal are bilateral trade relationships. Notice that, the extreme values of RTI, zero or one, are signals of strong symmetry or asymmetry in bilateral trade, respectively. Therefore, a huge $T I_{i j}$ not necessarily implies a high $R T I_{i j}$; conversely, $R T I_{i j}=1$ implies that trade is flowing in one direction only (from $i$ to $j$ or vice versa) and not necessarily means that it is about a huge amount of dollars.

Figure 1 (left panel) plots the empirical probability density function (PDF) of TI in logs for 1960 and 2000. The PDFs are similar in shape to the Log-normal distribution. Looking at different cross-sections, the PDF presents an interesting pattern: the left tail emerged remarkably, while the sample average and standard deviation increased. In contrast, the PDF of RTI displays a clear changing pattern in its shape, as portrayed for 1960 and 2000 in Fig. 1 (right panel). This evidence shows that trade asymmetries have increased: in 1960 the distribution is quite disperse in the $(0,1)$ interval with a larger probability mass towards zero, while in 2000 the distribution converges to a U-shaped (bimodal) shape with poles close to 0 

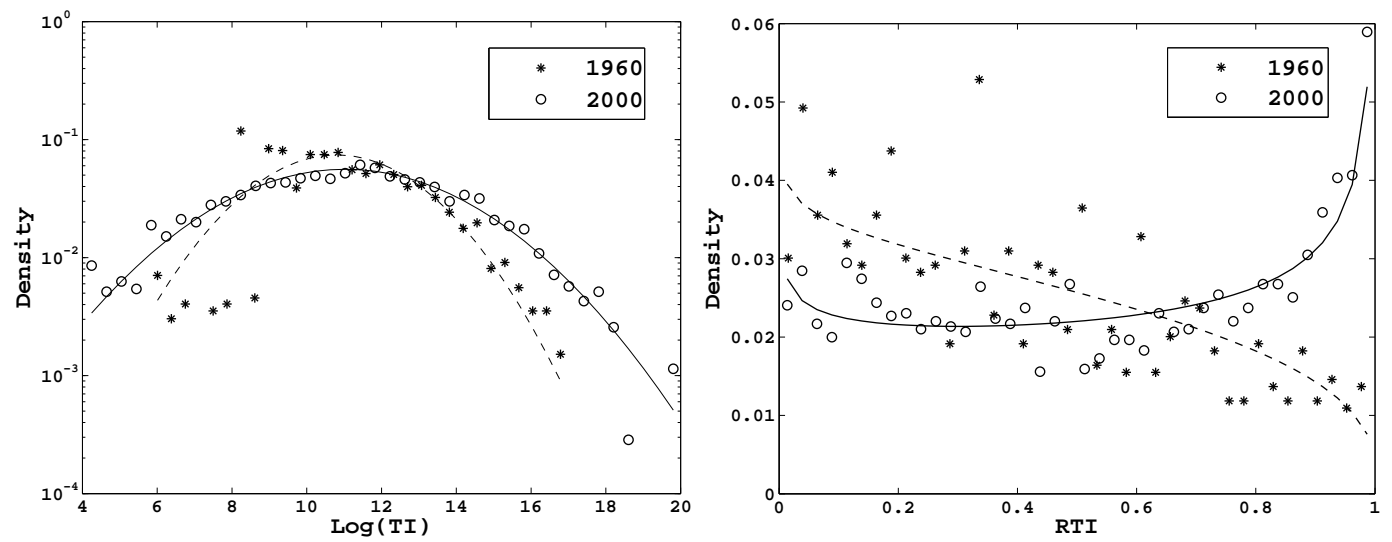

Figure 1: PDF of link trade-imbalances. Left: the PDF of $T I$ continuous and dash lines corresponds to log-normal adjustment for 1960 and 2000. Right: the PDF of RTI continuous and dash lines corresponds to beta adjustment for 1960 and 2000.

and 1 , with higher probability mass towards one. ${ }^{3}$

Given that in our dataset countries are the same in all cross-sections, the changes in the $T I$ and $R T I$ distributions are expected to derive from the existing bilateral relations and also from the creation/destruction of new/old ones. However, the period under study is characterized by strong globalization. In our sample, the density $(\rho)$ of trade relationships was about $50 \%$ in 1960 and $75 \%$ in $2000 .{ }^{4}$ Therefore, the international trade has become more extensive, i.e. more relationships were created instead of destroyed.

Trade imbalance link-weight definitions might be correlated with total trade driven by each link. First panel in Fig. 2 shows the scatter plot of TI versus TT. It is observed a positive log-linear relation among the absolute trade imbalance and the total trade. This suggests that for any bilateral relation the scale of its trade imbalance is proportional to its total trade: the more a couple of countries trade the higher the trade imbalance. Notice also that $T I$ tends to scatter near its maximum, i.e. the maximum possible imbalance occurs when trade flows in one direction only and, therefore $T I \rightarrow T T$.

Second panel in Fig. 2 shows the scatter plot of $R T I$ versus $T T$ for 2000. In relative terms, trade imbalances do not reveal any relation with total trade, the scatter plot is indeed quite disperse. However, a remark regarding to the extremes of trade symmetry must be done. It turns out that for links with very high total trade their corresponding relative trade imbalances are far from being clustered around $R T I=1$. Conversely, trade links running lower total trade are more attracted to cluster around $R T I=1$. This indicates that countries trading strongly have more reciprocal bilateral trade relations -huge trade flows going in one direction only might cause instabilities (and panic).

\footnotetext{
${ }^{3}$ The observations were adjusted to the Beta distribution and, accordingly, the estimated parameters satisfied $\alpha<\beta$ for 1960 and $\alpha>\beta$ for 2000 .

${ }^{4}$ The density is the total observed trade linkages divided by the maximum of possible trade linkages.
} 

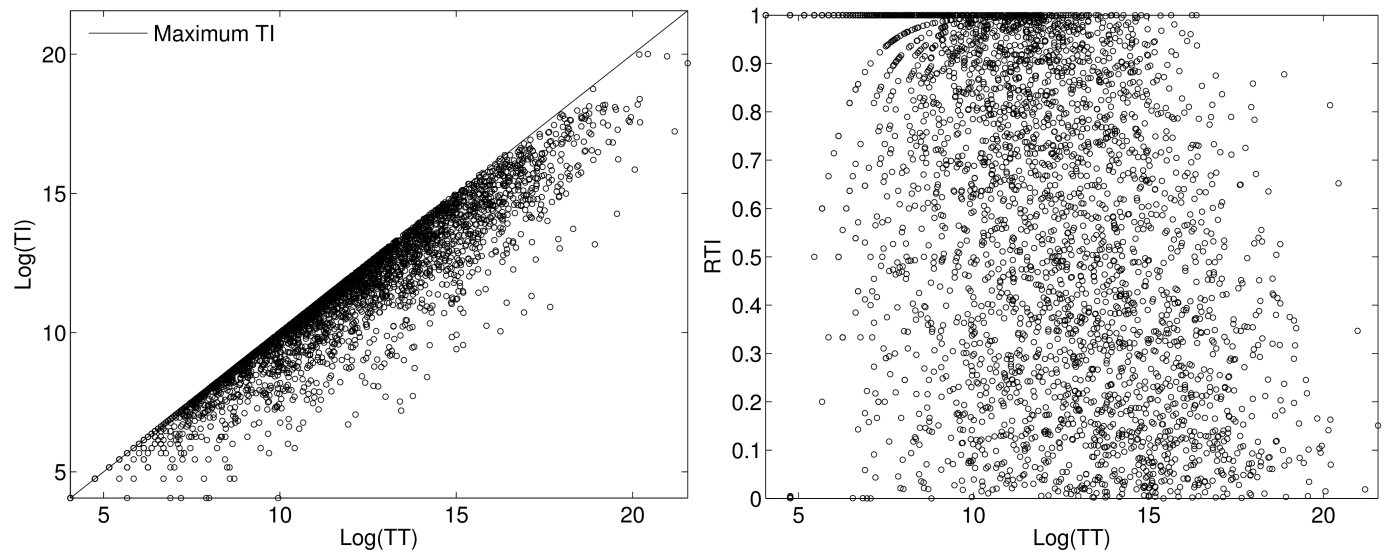

Figure 2: Trade imbalances versus total trade. Year: 2000. Left: $\log (T I)$ versus $\log (T T)$. Right: $R T I$ versus $\log (T T)$.

\subsection{Network Definitions}

Now, we define formally the networks employed in our approach.

Definition 1. The Total Trade Network (TTN) in a given year $t$ is represented by a weightedundirected graph, where the nodes are the $N$ countries and link weights are fully characterized by the $N \times N$ symmetric matrix with entries $T T_{i j}(t)=W_{i j}(t)+W_{j i}(t)$, i.e. the total trade between country $i$ and country $j$.

Definition 2. The Absolute Trade Imbalance Network (TIN) in a given year $t$ is represented by a weighted-undirected graph, where the nodes are the $N$ countries and link weights are fully characterized by the $N \times N$ symmetric matrix with entries $T I_{i j}(t)$, i.e. the absolute trade imbalance between country $i$ and country $j$.

Definition 3. The Absolute Relative Trade Imbalance Network (RTIN) in a given year $t$ is represented by a weighted-undirected graph, where the nodes are the $N$ countries and link weights are fully characterized by the $N \times N$ symmetric matrix with entries $R T I_{i j}(t)$ if and only if $T T_{i j}(t)>0$, i.e. the absolute relative trade imbalance between country $i$ and country $j$.

Definition 4. The Binary Total Trade Network, in a given year $t$ is represented by a binaryundirected graph, where the nodes are the $N$ countries and binary links are fully characterized by the $N \times N$ symmetric adjacency matrix $A$, with entries $a_{i j}(t)=1$ if and only if $T T_{i j}(t)>0$, i.e. it is observed a trade flow between country $i$ and country $j$.

It is worth noticing that all weighted-undirected networks share the same binary structure, since $W_{i j}=W_{j i}$ is never observed. Hence, the comparison of topological properties among networks is facilitated because network statistics for a given node are performed on the same 

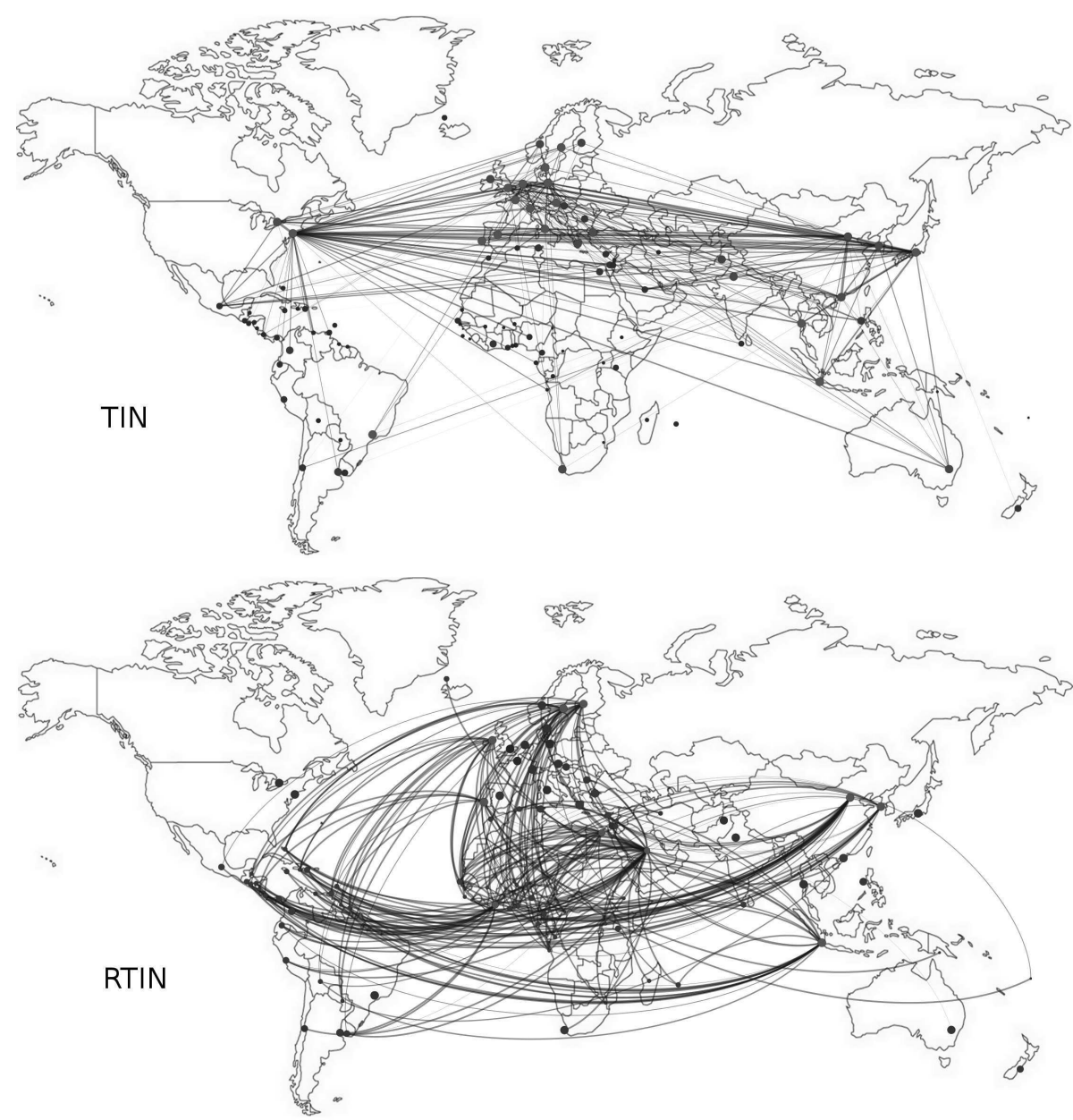

Figure 3: Maps of Global Trade Imbalances. Year: 2000. Top: TIN map. Bottom: RTIN map. Note: accordingly to each network, node's size is represented by country total number of trading partners and link's thickness by its weight. In the RTIN map links are curved to allow a better visualization of connection from African countries. In both, only the top $5 \%$ of edges are visible (around 475).

trade partners. In other words, we take advantage of the fact that all neighborhoods are identical across networks.

Figure 3 (top) plots the undirected weighted version of the TIN map in 2000. To attain a better visualization, considering that for our pool of countries the binary matrix is quite dense in this year $(\rho \approx 75 \%$ ), we first identify the top-10 countries with the highest total TI, and then we plot only the strongest connections of them, such that the number of visible links is the $5 \%$ of the possible in the whole network. This map allows one to appreciate the role of the developed economies concentrating the highest trade imbalances of the global trade. See also, that very few developing economies turn out to get connected to the top-10 most unbalanced nations, unlike trade intensive countries like China, Indonesia or Mexico (among others, in a lesser extent). 
Following the above mentioned visualization scheme, but using the top-10 countries with the highest total RTI, Fig. 3 (bottom) plots the undirected weighted version of the RTIN map in 2000. Notice that the number of link connections are the same in both maps (TIN and RTIN). Therefore, the TIN map, the RTIN map allows one to appreciate that practically all developing economies get connected to one of the 10 countries with huge total RTI, and many rich economies turn out unconnected. It is interesting, however, that many developed countries are very well connected to developing countries in the RTIN map, e.g. Korea, Ireland, Portugal, Norway, Sweden, or Finland, and that additionally to these countries other countries like China, Indonesia, Mexico, or Saudi Arabia are also well connected in both TIN and RTIN maps. Thus, in the RTIN map is more difficult to visualize a marked group of countries with very high imbalances, it can be recognized that most links connect the south of the globe, cf. the TIN map, in which most links connect the north.

\section{$3 \quad$ Weighted Topology}

\subsection{Network Statistics}

We use node statistics which are commonly employed in the trade network literature ( $\mathrm{Li}$ et al., 2003; Serrano and Boguñá, 2003; Garlaschelli and Loffredo, 2004; Fagiolo et al., 2009). These statistics allow studying node characteristics in terms of connectivity and clustering. In general, for a generic network matrix $W$, these are:

i) total node-strength $N S_{i}=W_{(i)} \mathbf{1}$, which measures the total weight intensity (DeMontis et al., 2005);

ii) total average nearest-neighbor strength $A N N S_{i}=A_{(i)} W \mathbf{1} / N D_{i}$, which computes the average weight of trade partners of a given node (DeMontis et al., 2005);

iii) the clustering coefficient $W C C_{i}=\left([W]^{[1 / 3]}\right)_{i i}^{3} / N D_{i}\left(N D_{i}-1\right)$, which proxies how strong are the edges of the triangles that are formed in the neighborhood of a node (Fagiolo, 2007);

where, $N D_{i}=A_{(i)} \mathbf{1}$ is the node-degree; $A_{(i)}$ is the $i$-th row of $A ;(W)_{i i}^{3}$ is the $i$ th entry on the main diagonal of $W \cdot W \cdot W$; and, $[W]^{[1 / 3]}$ stands for the matrix obtained from $\mathrm{W}$ after raising each entry to $1 / 3$.

To attain a better presentation of the topology analysis, we shall keep TTN as the benchmark network, given that it is equivalent to the well-known International Trade Network (ITN), in its weighted-undirected representation. In the ITN, links are defined as $\left(W_{i j}+W_{j i}\right) / 2$. The statistical properties of the ITN, in its undirected/directed or binary/weighted characterizations and evolution over time, have recently received a lot of attention in a number of 

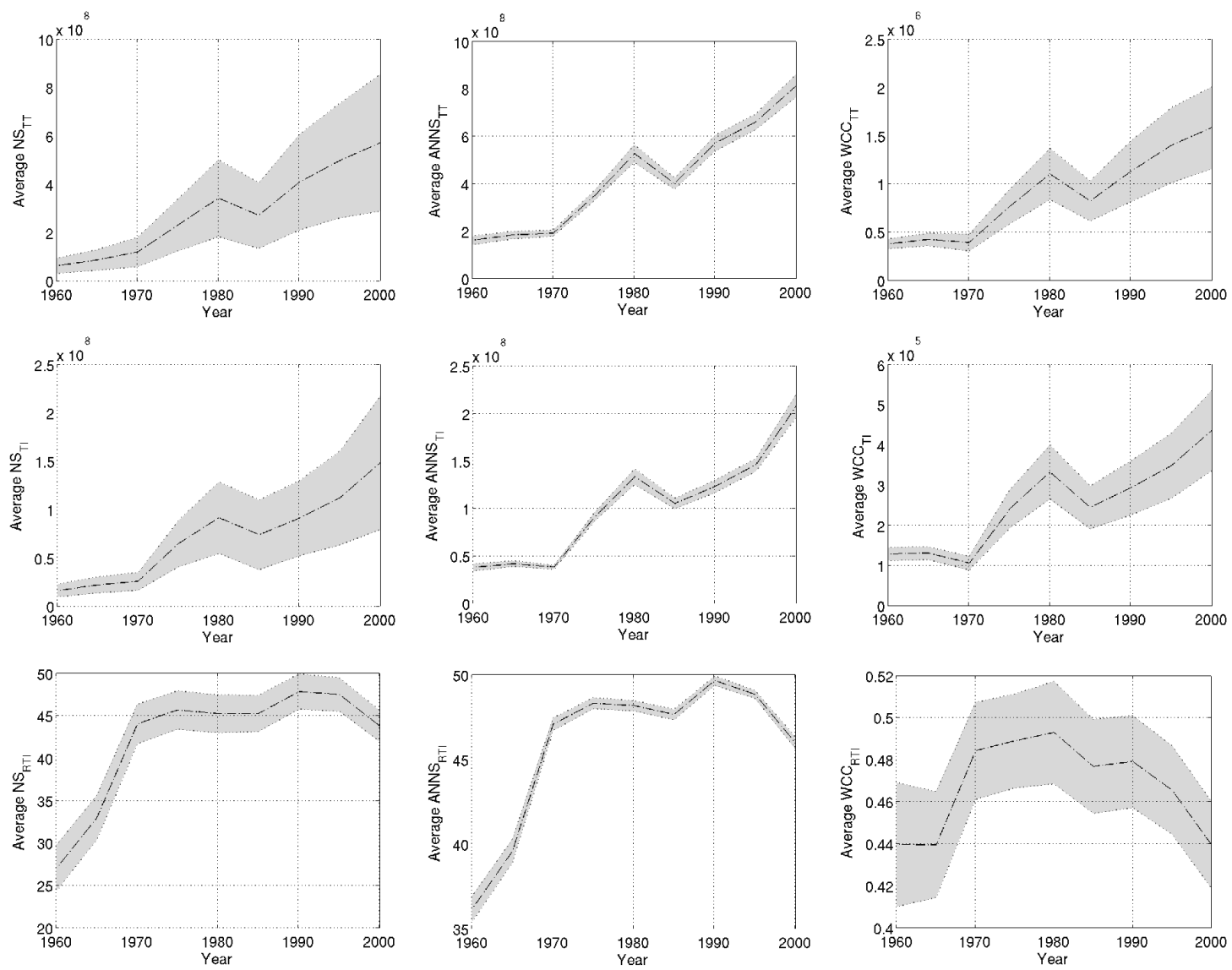

Figure 4: Observed network statistics averages. Note: the shaded bands correspond to the estimated standard deviation of the sample distribution of the corresponding statistic.

contributions. $^{5}$

Figure 4 plots the population averages of all statistics for each network. In the period under study, it is shown an impressive growth of international trade in real terms: averaged countries' total trade $\left(N S_{T T}\right)$ increased more than 4 times from 1960 to 2000. The strengthening effects are also observed in the trade relations maintained by countries' partners $\left(A N N S_{T T}\right)$ and trade-triangles formed around country-nodes $\left(W C C_{T T}\right)$. Together with the already mentioned increase in the density of trade linkages, the rise in these statistics suggests that world trade is becoming more intense and possibly more integrated. ${ }^{6}$

Looking at TIN statistics evolution, one can recognize that they grew with quite similar trends with respect to the corresponding TTN statistics, hinting that the dynamic network patterns of total trade and trade imbalances are closely related: the greater total trade, the

\footnotetext{
${ }^{5}$ See for example, Li et al. (2003); Serrano and Boguñá (2003); Garlaschelli and Loffredo (2004, 2005); Garlaschelli et al. (2007); Serrano et al. (2007); Bhattacharya et al. (2007, 2008); Fagiolo et al. (2008, 2009, 2010); Fagiolo (2010); Barigozzi et al. (2010); De Benedictis and Tajoli (2011).

${ }^{6}$ Actually, Bhattacharya et al. (2008) and Bhattacharya et al. (2007) find that the size of the group of countries controlling half of the worlds trade has decreased in the last decade.
} 
higher absolute trade imbalances. Thus, countries' total trade imbalance $\left(N S_{T I}\right)$, countries' trade partners average imbalances $\left(A N N S_{T I}\right)$, and imbalances of the trade-triangles around country-nodes $\left(W C C_{T I}\right)$ increased notably from 1960 to 2000 . Note that the population average of $N S_{T I}$ equals total world trade imbalances by the number of countries, which has grown steadily in the long term.

In contrast, RTIN statistics do not co-move with the corresponding TTN statistics, as expected, by definition the $R T I$ 's trend is removed. However, $N S_{R T I}$ increases remarkably between 1960 and 1970. In average countries were carrying almost a half of relative imbalances in 1960 as compared to 1970. This effect is observed for $A N N S_{R T I}$ as well. In addition, considering that there are 98 countries in our sample, those values from 1970 onwards turn out very large, because in average a country holds completely unbalanced relationships with approximately half of the other countries of the sample.

We should mention that reported clustering measures must be seen carefully. In network studies, it is common wisdom that clustering ranges between zero and one, mainly because links are defined in the same interval (clustering equal to 1 implies a fully and equally weightedconnected network). What it is interesting for us is how clustering distributes through countries. In our case, we are working with the original trade flows, which are in thousands of dollars, then TTN and TIN clustering size depends on the trade flow units. ${ }^{7}$ However, if one rescales TTN and TIN weights it turns out that clustering is a thousand times lower than the RTIN clustering, which properly ranges between zero and one. In any case, for RTIN, the average clustering is always very large, in contrast to the TTN in which it is large for high income economies only (Garlaschelli and Loffredo, 2005; Fagiolo et al., 2010). We shall analyze this in detail in Sec. 3.3.

\subsection{Country Rankings}

Table 1 reports the top-10 countries with highest statistics in each network for 1960 and 2000 . In the TTN high income economies trade more and are more central (making references to $N S_{T T}$ and $W C C_{T T}$ ), and $A N N S_{T T}$ is high for developing economies because they tend to be attached to trade hubs, i.e. high income economies. The number of country-name co-occurrences between $N S_{T T}$ and $W C C_{T T}$ is 7 for 1960 and 9 for 2000, resulting in a hierarchical arrangement. The core of this hierarchy is actually very stable. For instance, the pool of country that are in both years with high $N S_{T T}$ and $W C C_{T T}$ are: United States, United Kingdom, France, Germany, Italy, Canada, and Australia. But, in contrast, if one compares $A N N S_{T T}$ in both years finds no country-name co-occurrence. In other words, the core of the international trade has been very stable but the periphery has been more dynamic

\footnotetext{
${ }^{7}$ Without loss of generality, we kept them in that way, considering that later we perform econometric estimation of the trade flows and dealing with a normalizing factor may bias the analysis.
} 
Table 1: Top-10 countries with highest network statistics.

\begin{tabular}{|c|c|c|c|c|c|c|c|c|}
\hline \multicolumn{9}{|c|}{1960 Network Statistics } \\
\hline \multirow{2}{*}{$\begin{array}{l}N S_{T T} \\
\mathrm{USA}\end{array}$} & \multicolumn{2}{|c|}{$A N N S_{T T} W C C_{T T}$} & \multirow{2}{*}{$\begin{array}{l}N S_{T I} \\
\mathrm{USA}\end{array}$} & \multirow{2}{*}{$\begin{array}{l}A N N S_{T I} \\
\mathrm{PNG}\end{array}$} & \multirow{2}{*}{$\begin{array}{l}W C C_{T I} \\
\mathrm{PNG}\end{array}$} & \multirow{2}{*}{$\begin{array}{l}N S_{R T I} \\
\mathrm{ZAF}\end{array}$} & \multicolumn{2}{|c|}{$A N N S_{R T I} W C C_{R T I}$} \\
\hline & PNG & USA & & & & & $\mathrm{COG}$ & GNB \\
\hline GBR & $\mathrm{COG}$ & GER & GBR & $\mathrm{COG}$ & SAU & HKG & GNB & BEN \\
\hline GER & BEN & GBR & GER & BEN & USA & VEN & UGA & $\mathrm{COG}$ \\
\hline CAN & $\mathrm{BRB}$ & NGA & FRA & $\mathrm{BRB}$ & KOR & IND & PNG & GMB \\
\hline FRA & BLZ & AUS & CAN & BLZ & GER & DNK & KOR & MLI \\
\hline JPN & BHS & KOR & JPN & BHS & AUS & JPN & AGO & $\mathrm{BRB}$ \\
\hline ITA & GNB & CAN & NLD & GNB & GBR & NLD & MLI & MUS \\
\hline NLD & TGO & ITA & AUS & TGO & $\mathrm{COG}$ & PRT & CIV & PNG \\
\hline SWE & KOR & FRA & ITA & KOR & $\mathrm{BRB}$ & FRA & FJI & GIN \\
\hline AUS & NER & SAU & VEN & GAB & $\mathrm{CHN}$ & SWE & BEN & SAU \\
\hline \multicolumn{9}{|c|}{2000 Network Statistics } \\
\hline$N S_{T T}$ & $A N N S_{T T}$ & $W C C_{T T}$ & $N S_{T I}$ & $A N N S_{T I}$ & $W C C_{T I}$ & $N S_{R T I}$ & $A N N S$ & ${ }_{I} W C C_{R T I}$ \\
\hline USA & GNB & USA & USA & GNB & USA & SAU & SLE & HTI \\
\hline GER & FJI & GER & $\mathrm{CHN}$ & FJI & JPN & $\mathrm{CHN}$ & SYR & SLE \\
\hline JPN & $\mathrm{MOZ}$ & JPN & JPN & $\mathrm{MOZ}$ & $\mathrm{CHN}$ & IDN & ETH & AGO \\
\hline GBR & PNG & GBR & HKG & PNG & GER & FIN & GNB & NIC \\
\hline $\mathrm{CHN}$ & TCD & FRA & GER & SLE & NLD & CIV & $\mathrm{MOZ}$ & BLZ \\
\hline CAN & SLE & $\mathrm{CHN}$ & NLD & TCD & KOR & SWE & GUY & GNB \\
\hline FRA & CAF & ITA & CAN & $\mathrm{CAF}$ & GBR & KOR & AGO & GMB \\
\hline ITA & UGA & NLD & KOR & UGA & ITA & IRL & MDG & BRB \\
\hline MEX & BFA & MEX & ITA & GMB & SAU & EGY & TCD & SLV \\
\hline NLD & GMB & KOR & GBR & AGO & MEX & PRT & BHS & SUR \\
\hline
\end{tabular}

Note: see Appendix A for the list of country codes

(cf. Reyes et al., 2008). This might not be surprising since mostly developing countries are in the periphery and these have more heterogeneous trading and growing patterns.

Similarly, the TIN is characterized by a hierarchical arrangement as well, especially in 2000 when there are 8 country-name co-occurrences between $N S_{T I}$ and $W C C_{T I}$ (instead of 4 in 1960), and there is no country-name co-occurrence between $N S_{T I}$ and $A N N S_{T I}$ (in both years). The pool of countries that are in both years with high $N S_{T I}$ and $W C C_{T I}$ are: United States, United Kingdom, and Germany. Notice that those countries are quite central in TTN in 1960 as well, but in 2000 more countries join this club of highly unbalanced and clustered: Italy, Netherlands, Japan, and China.

Conversely, for RTIN the hierarchical arrangement is absent. There are no country-name co-occurrences between network statistics. Few countries show up in the same statistic in both years: Sweden and Portugal in $N S_{R T I}$; Angola and Guinea-Bissau in $A N N S_{R T I}$; and Barbados, The Gambia, and Guinea-Bissau in $W C C_{R T I}$. It is interesting that no member 

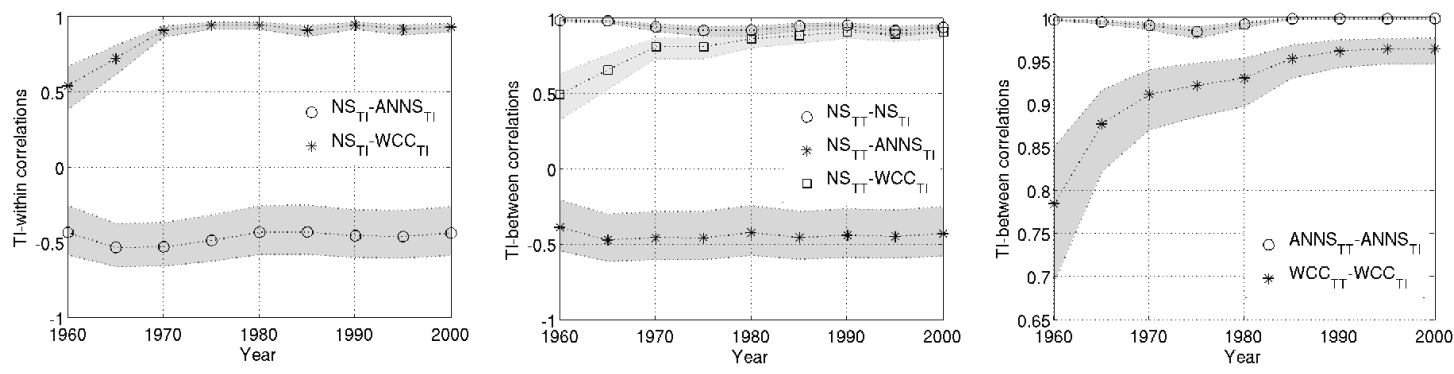

Figure 5: Observed cross-correlations of TIN statistics.

of the above-described rich-club of countries with high $N S_{T T}$ and $N S_{T I}$ is highly clustered in the RTIN. Nonetheless, we can highlight that in 1960 the country-name co-occurrences between $N S_{T T}$ and $N S_{R T I}$ are: France, Netherlands, Sweden, and Japan; and in 2000 just China.

\subsection{Correlation Structure}

Now, we move our attention to Pearson's correlations among statistics. Many important topological information of networks can be derived from the study of the correlation between network statistics. For instance, with $\operatorname{corr}(N S, A N N S)$ one asks whether our networks exhibit assortative (or disassortative) patterns, i.e. if countries connect among them because they have similar weights; and with $\operatorname{corr}(N S, W C C)$ one asks whether country local clustering is associated with country weighted connectivity. Notice that each network is characterized by three statistics and, therefore, 36 different correlations. However, and without loss of generality, it is enough to focus on a small set of possible correlations, which contain critical information about the structure, e.g. within- and between-network assortativity and strengthclustering correlations.

The correlation patterns of TIN indicate strong similarities with the TTN's topology. Figure 5 plots the correlations concerning the TIN statistics. The within network correlations, first panel in figure, show that the TIN is within-dissasortative, $\operatorname{corr}\left(N S_{T I}, A N N S_{T I}\right)<0$ : the trading partners of countries with larger total trade imbalances have in average lower total trade imbalances. The $\operatorname{corr}\left(N S_{T I}, W C C_{T I}\right)$ is positive and very high: the more unbalanced a country is, the stronger unbalanced trade-triangles it belongs. These effects together are signs of the "rich-club" property (Colizza et al., 2006): few countries are highly interconnected and carry an important extent of the international imbalances, we shall explore this evidence in detail in Sec. 3.4.

The second panel in Fig. 5 shows the between-correlations of the TIN against $N S_{T T}$, both node-strengths are highly correlated in most cross-sections: countries' total trade imbalances are positive related to their total trade. Additionally, the TIN is between-disassortative $\left(\operatorname{corr}\left(N S_{T T}, A N N S_{T I}\right)<0\right)$ : trade partners of big traders tend to have less total imbal- 

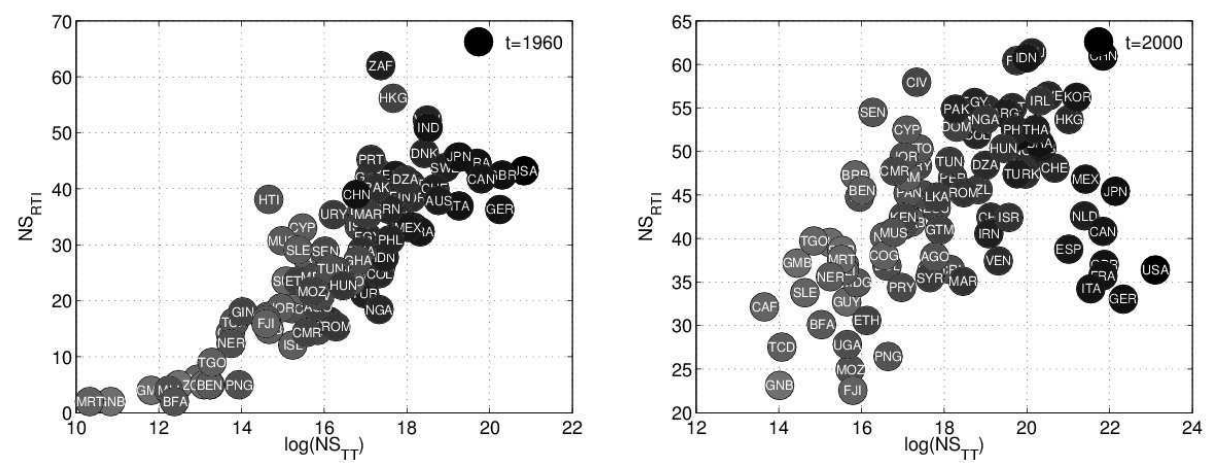

Figure 6: RTIN-TTN node-strengths scatter plots. Left: 1960, and right: 2000. Note: point's darkness proxies the corresponding country's GDP. See Appendix A for the list of country-name abbreviations.

ances in average. The relation total trade strength and trade imbalance clustering is positive $\left(\operatorname{corr}\left(N S_{T T}, W C C_{T I}\right)>0\right)$ : locally country clustering of imbalances can be associated to its total trade intensity. Finally, to confirm the similarities between TTN and TIN the correlations $\operatorname{corr}\left(A N N S_{T T}, A N N S_{T I}\right)$ and $\operatorname{corr}\left(W C C_{T T}, W C C_{T I}\right)$ are very high, as shown in the third panel.

Accordingly, as the TTN, the TIN is also disassortative with a very hierarchical structure, where the countries that trade more are more unbalanced and central, and have neighbors with lower total trade and for this reason less unbalanced. The fact that TIN and TTN node-strengths are highly correlated might explain why the TIN and the TTN have similar architectures. Actually, in Fig. 2 we observed that in logs the TTN and TIN link-weights are also positive correlated. This highlights the importance of some countries at determining the topology and functioning of the world trade system (those with high node strength and clustering). This agrees with Serrano et al. (2007), who showed that there is a small set of structural links in the world trade system.

The RTIN differs significantly from the TIN, especially because between $N S_{R T I}$ and $N S_{T T}$ is not detected a robust correspondence along cross-sections, as Fig. 6 suggests for 1960 and 2000. In this figure, each point represents country's node-strengths in TTN (in logs) and RTIN coordinates, and point's darkness proxies the country's GDP. In $1960 N S_{R T I}$ and $\log \left(N S_{T T}\right)$ are positively correlated, the most unbalanced countries were those with higher total trade including some rich-club members- in comparison with middle and low-GDP countries -which by then were recognized for being less open to trade.

In 2000, this positive pattern is broken. It turns out that most countries increase their absolute relative imbalances and, therefore, more asymmetric trade relationships. This shift leads to an inverse U-shaped scatter plot, where the $N S_{R T I}$ for many developed countries increased comparatively less when compared with developing economies. The most evident changes are observed for most 'catching-up' economies. For example, China became one of 

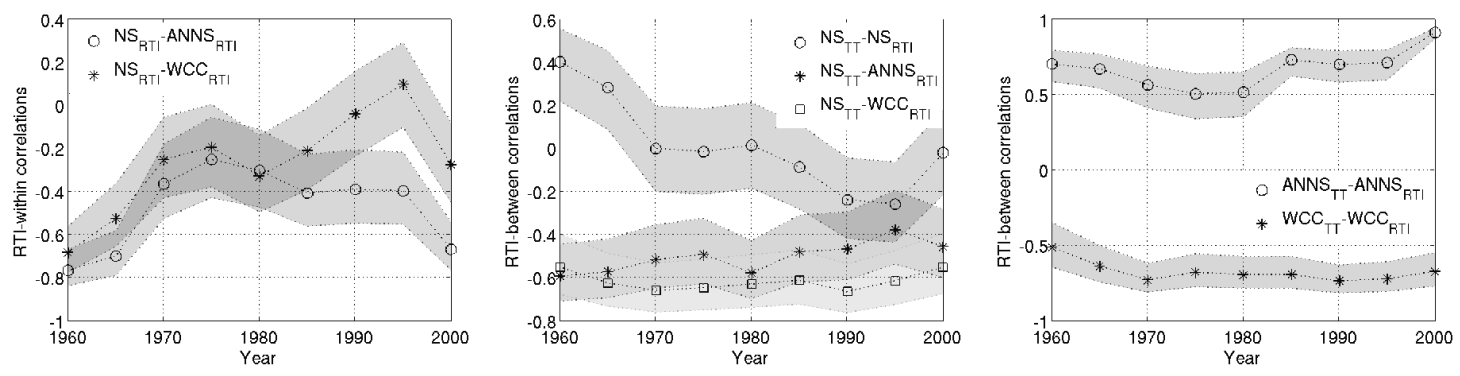

Figure 7: Observed cross-correlations of RTIN statistics.

the countries carrying huge total relative imbalances, by 1960 China's $N S_{R T I}$ was close to 40 and for 2000 something above 60 . It is remarkable that in our data there are just 98 countries and there is an important group of countries (most of them developing) with $N S_{R T I}>50$. It could be read as if on average those countries have very asymmetric trade relations with more than half of the countries in the sample, and also indicates that through time core countries manage to have comparatively more equilibrated trade relationships.

Figure 7 (first panel) shows the within-correlations for the RTIN statistics. As expected from the above discussion, this architecture has less robust patterns. However, it is disassortative in all cross-sections $\left(\operatorname{corr}\left(N S_{R T I}, A N N S_{R T I}\right)<0\right)$, and the correlation among $N S_{R T I}$ and $W C C_{R T I}$ is negative, although sometimes not significant. Therefore, local clustering in RTIN is not associated with country relative imbalances connectivity.

Figure 7 (second and third panel) shows the between-correlations for the RTIN. It is observed that since 1970 the correlation between node strengths is very low and non-significant. Nonetheless, it is possible to observe other robust correlations in all cross-sections. The between strength-clustering correlation is negative $\left(\operatorname{corr}\left(N S_{T T}, W C C_{R T I}\right)<0\right)$, i.e. local clustering in RTIN tends to be low for countries with higher total trade. Therefore, the between clustering-clustering correlation is negative $\left(\operatorname{corr}\left(W C C_{T T}, W C C_{R T I}\right)<0\right)$, i.e. high clustered countries in total trade tend to have less clustered relative unbalanced relationships. This means that even if big traders of the rich-club exchange between them high fluxes of money due to trade imbalances (ass seen in the TIN) they tend to have more reciprocal trade relationships.

The RTIN has a between-disassortativity pattern $\left(\operatorname{corr}\left(N S_{T T}, A N N S_{R T I}\right)<0\right)$. It indicates that countries with higher total trade tend to have neighbors with lower total relative imbalances (in average). It is also observed that $\operatorname{corr}\left(A N N S_{T T}, A N N S_{R T I}\right)>0$, i.e. the neighborhoods that on average trade more are also more unbalanced, in relative terms. This effect was also observed in the TIN. It relates to the fact that relative trade imbalances are widely diffused in the trade network (which is quite dense in its binary structure), therefore, one could say that this a consequence of the extensive terms of trade. In a globalized world the more connected neighborhoods reveal more relative trade imbalances -asymmetries (in 
trade) are everywhere.

Accordingly, the RTIN architecture has remarkable differences with respect to TTN, and therefore TIN. The most important difference is that clustering is not concentrated in few countries and, for this reason a hierarchical arrangement is absent. The lack of a significant correlation structure among TTN and RTIN node-strengths, and considering that developed economies have higher total trade, reveals that high total relative imbalances are not a particular characteristic of some country size level. However, our analysis indicates that countries embedded in the core of international trade have less likelihood of running large total relative imbalances. Instead, the higher imbalances are driven by emerging economies that trade closely to the trade-core and with many other less developed countries (cf. Reyes et al., 2008).

\subsection{Rich-Club Structure}

We have seen that TIN and RTIN differ in how node-strengths correlate with clusterings. In the TIN, the existence of a positive within strength-clustering correlation coupled with withindissasortativity indicates that, in this network architecture, strong trade imbalances are concentrated between a small set of countries. Conversely, in the RTIN the strengths-clustering correlations, $\operatorname{corr}\left(N S_{R T I}, A N N S_{R T I}\right)$ and $\operatorname{corr}\left(N S_{T T}, A N N S_{R T I}\right)$, are both negative, coupled with the between- and within-disassotrtativity, point that, in the RTIN architecture, strong relative trade imbalances are unlikely concentrated in a small set of countries.

To explore the evidence, we have computed the size $M$ of the wighted rich-club ratio $(W R C R)$, defined as the percentage of trade imbalances carried by the links between these $M$ countries, where countries have been sorted in a descending order according to their total strength (Colizza et al., 2006; Opsahl et al., 2008). More precisely, the $W R C R$ for a rich-club size $1<M \leq N$ is

$$
W R C R(M)=\frac{\sum_{i=1}^{M} \sum_{j=1}^{M} \tilde{m}_{i, j}}{\sum_{i=1}^{N} \sum_{j=1}^{N} \tilde{m}_{i, j}},
$$

where, $\tilde{m}_{i, j}$ stands for the link-weight $(T I$ or $R T I)$ in the sorted network-matrix representation. Notice that the denominator in Eq. (3) equals the global trade imbalance, according to the TIN or the RTIN.

Figure 8 plots the relation between the size $M$ of the club and $W R C R$ for both trade imbalance networks in 2000. It is also added the expected value of the $W R C R$ in comparable networks where the binary structure is taken as given and weights are reshuffled uniformly at random. The $W R C R$ curve for the TIN in 2000 increases rapidly with $M$, it is always larger than the expected in a comparable reshuffled TIN (keeping fixed the binary structure). It turns out that in the TIN a rich-club effect is confirmed. For example, around only 10 countries run for $40 \%$ of the global imbalances.

The rich-club effect is also characteristic of the TTN and the international trade network 

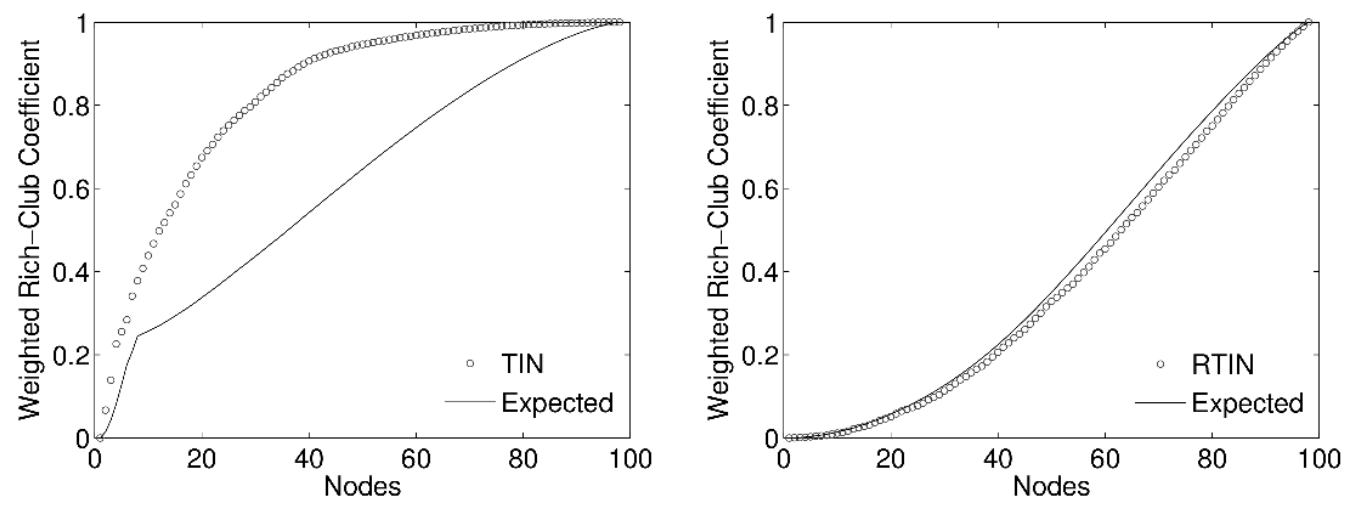

Figure 8: Weighted rich-club coefficient ratio (WRCR). Year: 2000. Left: TIN, and right: RTIN. Note: 'Expected' is the value of the WRCR in random networks where link weights are reshuffled over the existing binary architecture.

(Fagiolo et al., 2009). In the same way, for example, in the TTN around only 10 countries run $40 \%$ of the world total trade. As seen in Table 1, the top-ten countries with high total trade have also high trade imbalances, in other words, there are a lot of ties among the TIN and TTN rich-clubs.

The rich-club effect is absent for the RTIN. For this network, we observe that in 2000 the $W R C C$ curve increases slowly with $M$, it is actually below -but close to- the expected curve in a comparable reshuffled RTIN (keeping fixed the binary structure), see right panel in Fig. 8. For example, we would need more than a half of the countries in our sample to account for $40 \%$ of the total sample relative trade imbalances. In accordance with the analysis of the correlation structure of RTIN statistics, this suggests that trade asymmetrical reciprocity prevail for most world countries.

\section{Predicting the Architecture: Null versus Gravity Model}

In this section, we try to reproduce the networks' structure starting from random weighteddirected trade networks, i.e. we model the weighted-directed ITN to then reproduce the structure of TTN, TIN and RTIN at the same time. Recently, the architecture of the ITN has been studied by fitting null network models on the trade network (Fagiolo et al., 2012), or by fitting trade flows with the gravity model (Dueñas and Fagiolo, 2013). Therefore, we are interested in the scope of this kind of strategies to reproduce the structures of the global trade imbalances.

Null models, instead of being based on economic fundamentals, aim at explaining the observed patterns constraining some observed network statistics (or regularities), which the researcher considers that are determinant in the network generation process itself. Maslov and Sneppen (2002) proposed a model where links are reshuffled but keeping the in- and 
out-degree of each node constant, then the insight behind is that it is enough keeping fixed country's abilities to create linkages and grant trade flows, and less importance is given to the bilateral relations. At first glance, it is possible to say that null models are based on complex statistical measures lacking of economic meaning. For this reason, when this approach is considered one gives up the ability of explanation -as we rely on the chosen regularities. In any case, whether the null model is successful or not, there is a theoretical reward. When it is successful, the question is which are the economic fundamentals that explain the considered regularities. When it fails, we should ask for better null models and recognize that what we observe relies on economic processes that are beyond node/link observed properties, i.e. even more structural features.

Additionally, we study the explanatory scope of the traditional Gravity Model (GM) in international trade, which is equipped with node and link independent variables, which in principle are the main source of asymmetry and heterogeneity. The gravity equation in its standard specification can be written as,

$$
W_{i j}=\exp \left\{x_{i j} \cdot \beta\right\} \eta_{i j}
$$

where,

$$
x_{i j}=\left\{\log \left(Y_{i}\right), \log \left(Y_{j}\right), \log \left(X_{i}\right), \log \left(X_{j}\right), Z_{i}, Z_{j}, d_{i j}, D_{i j}, \gamma_{i}, \gamma_{j}\right\}
$$

$i, j=1, \ldots, N, i \neq j ; Y_{i}$ is the annual GDP for country $i$; $d_{i j}$ the distance between both countries; $X_{i}=\left\{\operatorname{area}_{i}, \operatorname{pop}_{i}\right\}$ the vector of country-specific macro variables; $D_{i j}=\{$ contig, comlang_off, comcol, colony, comrelig, comcur, rta $\}$ the vector of link-specific variables indicating barriers to trade; $Z_{i}=\{$ landl, continent $\}$ are country-specific dummies; $\gamma$ control for country-exporter-importer fixed effects; and it is assumed that $E\left[\eta_{i j} \mid Y_{i}, Y_{j}, d_{i j}, \ldots\right]=1$. See Appendix B for a complete description of the employed variables and sources.

One important issue of the gravity model are the predictions of bilateral relationships, i.e. binary structure of the trade network. Dueñas and Fagiolo (2013) found that the GM performs very badly when asked to predict the presence of a link, or the level of the trade flow that it carries, whenever the binary structure must be simultaneously estimated. Given that, we compare the GM with the null model proposed by Maslov and Sneppen (Maslov and Sneppen, 2002), but keeping the binary structure fixed for the GM predictions, i.e. we predict the trade flow for the links that carry a positive trade flow only. Our purpose here is to understand the asymmetries starting from the prediction of the trade flows. To do this, we choose the model that best describes the architecture of the international trade network.

We estimate the gravity model over a broad range of techniques and specifications. We used standard OLS and Poisson pseudo-maximum likelihood (PPML) models. In addition, we used the standard specification with and without country-exporter-importer fixed effects. When fixed effects are used, the specification test allowed us to rule out country specific 
Table 2: GM-PPML estimation of trade flows (Anderson and van Wincoop's specification (Anderson and van Wincoop, 2003)). Year: 2000.

\begin{tabular}{llllll}
\hline \hline Regressor & 1960 & 1970 & 1980 & 1990 & 2000 \\
\hline $\ln \left(d_{i j}\right)$ & $-0.69^{* * *}(0.05)$ & $-0.79^{* * *}(0.05)$ & $-0.85^{* * *}(0.04)$ & $-0.80^{* * *}(0.04)$ & $-0.74^{* * *}(0.04)$ \\
contig & $0.31^{* *}(0.10)$ & $0.24^{* *}(0.08)$ & $0.38^{* * *}(0.08)$ & $0.46^{* * *}(0.09)$ & $0.47^{* * *}(0.08)$ \\
comlang_off & $0.36^{* *}(0.11)$ & $0.48^{* * *}(0.09)$ & $0.40^{* * *}(0.09)$ & $0.47^{* * *}(0.08)$ & $0.39^{* * *}(0.07)$ \\
comcol & $-1.04^{* *}(0.35)$ & $-0.37^{*}(0.18)$ & $-0.48^{*}(0.20)$ & $-0.15(0.19)$ & $0.25(0.15)$ \\
colony & $0.75^{* * *}(0.16)$ & $0.55^{* * *}(0.13)$ & $0.15(0.11)$ & $-0.14(0.11)$ & $-0.14(0.1)$ \\
comrelig & $-0.31^{*}(0.13)$ & $0.07(0.12)$ & $-0.21(0.12)$ & $-0.08(0.10)$ & $0.09(0.10)$ \\
comcur & $1.80^{* * *}(0.21)$ & $1.20^{* * *}(0.22)$ & $0.10(0.17)$ & $-0.22(0.32)$ & $0.02(0.09)$ \\
rta & $0.19(0.10)$ & $0.62^{* * *}(0.07)$ & $0.13(0.07)$ & $0.12(0.06)$ & $0.46^{* * *}(0.07)$ \\
Fixed effects & YES & YES & YES & YES & YES \\
No. Obs & 9506 & 9506 & 9506 & 9506 & 9506 \\
\hline \hline
\end{tabular}

Notes: $i=$ exporter, $j=$ importer; standard error in paren-

thesis; and ${ }^{*} p<0.05,{ }^{* *} p<0.01,{ }^{* * *} p<0.001$

variables. ${ }^{8}$ All econometric techniques showed similar performances at describing the overall properties of the predicted networks. However, we picked only the PPML with fixed effects, because it provided marginally the closest predictions of the overall network topologies. All estimates are shown in Table 2, sizes and signs are consistent with commonly reported values in GM studies in international trade (Bergstrand, 1985; Anderson and van Wincoop, 2003; Baldwin and Taglioni, 2006; Santos Silva and Tenreyro, 2006).

In the standard GM framework, with symmetric trade barriers (tariffs), the sources of trade asymmetries are accounted by differences in country specific parameters, in our case the country-exporter-importer dummy parameters. Figure 9 shows the scatter plot of the estimated fixed effects parameter versus the country $\log$ (GDP) for 1960 and 2000. In agreement with the gravity approach, in both cross-sections it is observed a positive relation among the GDP and the estimated exporter-importer fixed effects. Additionally, notice that independently for each country, the differences between these parameters are more evident in 2000 than in 1960, suggesting stronger country importer-exporter profile asymmetries over time. And interestingly enough, the difference $\gamma_{i 1}-\gamma_{i 2}$ is quite similar for all countries.

To fully simulate our networks, we employ many independent samples of the trade network matrix, then in each iteration the corresponding TTN, TIN and RTIN are computed, together with all interesting statistics and correlations. Finally, the simulated topological variables are averaged and compared with the observed ones. This process was iterated 10,000 times for the null model and the gravity model predictions. In the former case, we employed the methodology proposed by Maslov-Sneppen model (Maslov and Sneppen, 2002), which has already been sketched above. In the latter case, we used the integer predicted bilateral trade

\footnotetext{
${ }^{8}$ Santos Silva and Tenreyro (2006) showed that country specific (e.g. GDPs) elasticities cannot be identified when fixed effects are used. Additionally, all our results are robust to the representation used by Anderson and van Wincoop (2003), which is one of the most commonly used in GM exercises.
} 

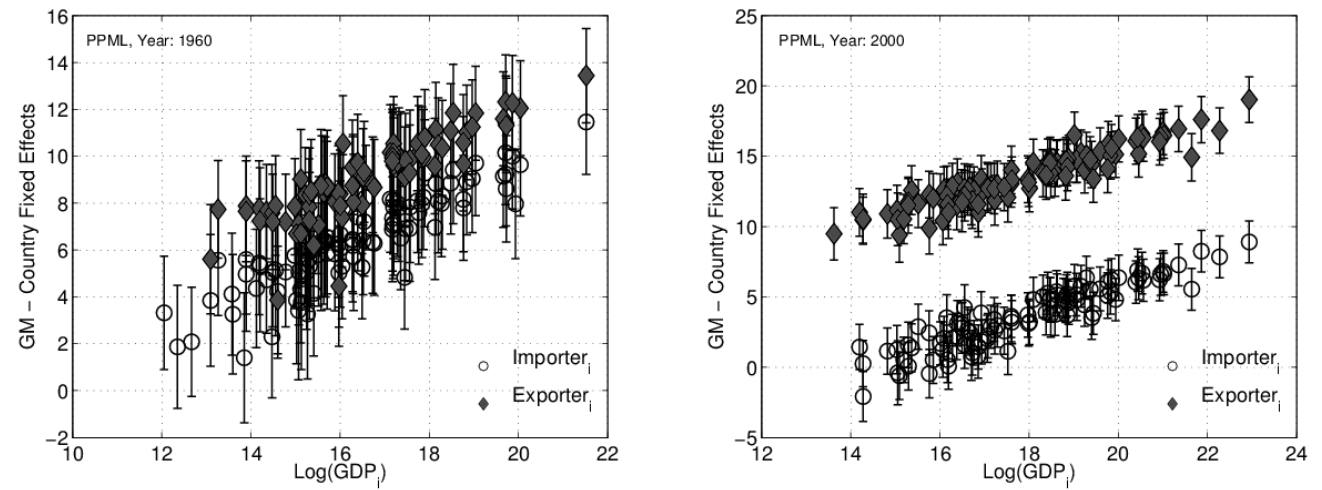

Figure 9: Estimated GM-PPML importer-exporter fixed effects versus GDP. Left: 1960 and right: 2000 .
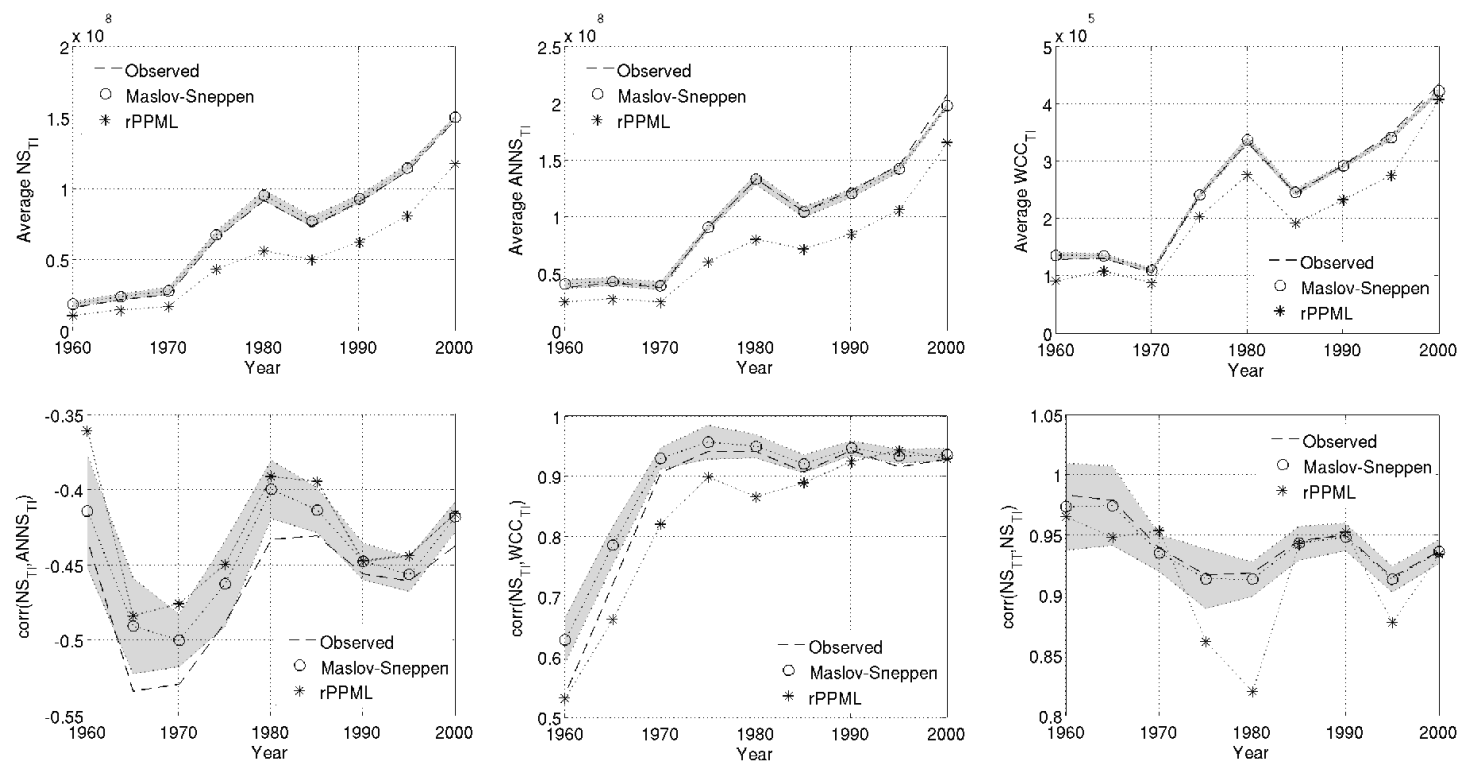

Figure 10: Observed versus Null- and GM-predictions of TIN statistic averages and correlations. Null: Maslov-Sneppen's rewiring; rPPML: PPML estimated for the full sample, and predictions restricted to non-zero flows only. 95\% confidence bands are displayed as error bars around predicted values.

flows by the GM, we then simulated directed trade flows $\tilde{W}_{i j}$ using their corresponding Poisson distribution, this is $\operatorname{Prob}\left\{\tilde{W}_{i j}\right\}=\hat{\mu}_{i j}^{\tilde{W}_{i j}} \exp \left(-\hat{\mu}_{i j}\right) / \tilde{W}_{i j}$ !, where $\hat{\mu}_{i j}$ corresponds to the PPML estimation, the predicted trade matrix is restricted to couples of countries such that $W_{i j}>0$, i.e. we put ourselves in the best of all possible situations (cf. Dueñas and Fagiolo, 2013), keeping untouched trade-zeros or binary structure.

Regarding the Maslov-Sneppen model predictions, Fig. 10 plots the simulated TIN statistic averages and correlations. This model provides close predictions of the TIN topology structure and the simulated confidence intervals contain the observed values in some cross-sections. However, one important remark must be done here. The Maslov-Sneppen method might be 

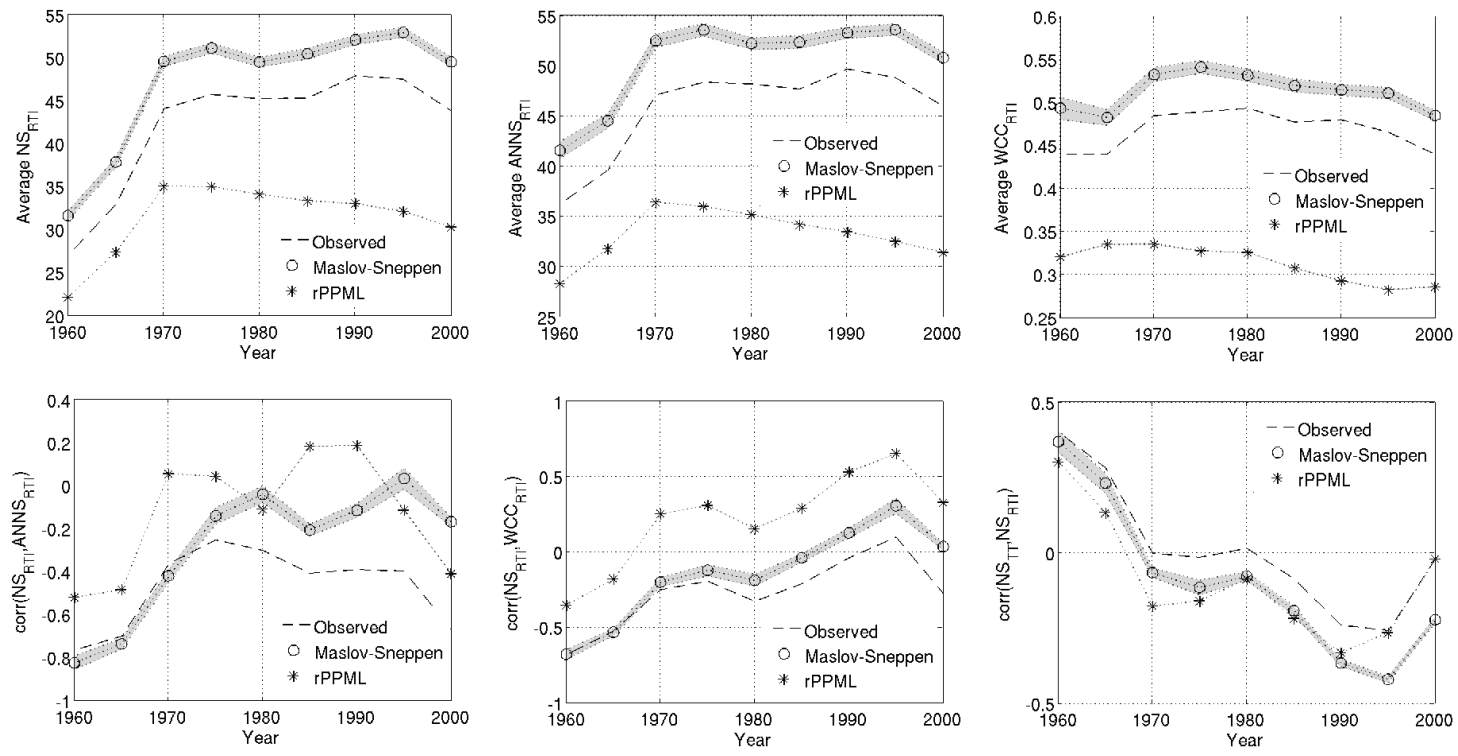

Figure 11: Observed versus Null- and GM-predictions of RTIN statistic averages and correlations. Null: Maslov-Sneppen's rewiring; rPPML: PPML estimated for the full sample, and predictions restricted to non-zero flows only. $95 \%$ confidence bands are displayed as error bars around predicted values.

biased in dense networks because there are no degrees of freedom for reshuffling (Roberts and Coolen, 2012). Given that we selected a balanced cross-section, the pool of trading world countries was notably reduced. This implies that space for randomization is reduced as well. For instance, the degree sequence for many developed economies is almost complete: they export and import from almost all sources in the dataset. Nevertheless, we keep this results because they represent a good benchmark to compare with the gravity model.

In the case of predicting the RTIN topology, see Fig. 11, the Maslov-Sneppen method shows significantly lower predictive power; some trends are roughly captured. Consistently with what it is observed in the ITN (Squartini et al., 2011a,b), it is not enough to keep inand out-degree sequences to account for the weighted disassortativity and clustering-strength correlation. Therefore, it is expected a low performance at reproducing TTN, TTN and RTIN.

We should interpret the results in the light of the underlying complexity of the global imbalances structure. This means that the sequences of trade degrees contain insufficient information to predict the topological structure of trade imbalances. The fact that the MaslovSneppen method works better for the TIN than for the RTIN is consistent with the high value of $\operatorname{corr}\left(N S_{T T}, N S_{T I}\right)$, although this model does not control for strength sequences. This is not the case for RTIN, because $N S_{T T}$ and $N S_{R T I}$ are uncorrelated in most cross-sections. This reinforces the view that relative trade imbalances rely on more profound features of countries and their bilateral relations. To predict better the RTIN topology, we might need to control beyond in- and out-degree trade sequences.

Regarding the GM predictions, also in Figs. 10 and 11 are plotted the simulated TIN 
and RTIN statistic averages and correlations. The restricted PPML model (rPPML) provides narrowed error bands but completely misplaced predictions. Just in the case of the TIN topology, the rPPML predictions roughly captures the long-term trends of the averaged statistics. These results expose the problems of the GM at accounting properly for trade asymmetries.

But, why does the GM perform so badly? One important remark must be made on the link symmetry of the employed explanatory variables and residuals. Notice that these variables are commonly employed to proxy bilateral trade costs. The symmetric assumption is done quite frequently in theoretical models and is useful to derive a system of structural equations and estimate a gravity model (Anderson and van Wincoop, 2003; Feenstra, 2004). Therefore, the interpretation of the link specific parameters are restricted to be only an "average" of the barriers effects in both directions as it is stated by Anderson and van Wincoop (2003). At first glance, this limitation is not a dramatic problem for our purposes, considering that we were actually interested in the prediction of imbalances in absolute values, which are by definition symmetric. However for the estimation of the trade flows it might be a sensitive step (Bergstrand et al., 2013). In a nutshell, residuals are asymmetric $\left(\eta_{i j} \nsim \eta_{j i}\right.$, see Eq. (4)) and, more importantly, they contain an important extent of the underlying complexity that determines the structure of the networks of imbalances. This complements the discussion presented by Fagiolo (2010), who finds that the GM residual displays marked signatures of a complex system, where many small-sized but trade-oriented countries either play the role of local hubs or attract large and rich countries.

\section{Concluding Remarks}

In this paper, we have studied the trade imbalances for world countries using a complexnetwork approach. Global trade imbalances have been recognized as a destabilizing factor of the international economics. The recent processes of globalization, understood as the strengthening of international trade, has come together with increasing trade asymmetries revealed in high and intense trade imbalances. We show that the absolute trade imbalance network has a topology quite similar to the international trade network. In the TIN countries that trade more are more unbalanced and central, and have neighbors with lower total trade and less unbalanced. This network is characterized by a rich-club effect: just 10 countries drive more than $40 \%$ of the global imbalances in absolute values.

Conversely, the RTIN topology has remarkable differences with respect to the TIN. In the RTIN clustering is not concentrated in few countries, and especially higher for developing economies, and a rich-club effect is absent. This shows that while rich economies are more unbalanced in absolute terms, they also have less relative unbalanced relations. Another remarkable result is that many catching up economies are highly unbalanced in relative terms; in average many of them have completely asymmetric trade relations with more than a half of 
countries considered in the sample. This highlights the role of emergent economies as drivers of international trade.

The econometric predictions allow us to conclude that the gravity model, the work-horse theoretical reference in international trade, provides unsatisfactory explanations of the excess of trade. Gravity residuals are asymmetric and, more importantly, they contain an important extent of the underlying complexity that determines the structure of the networks of imbalances.

One important implication of our results is that the evolution of the international trade has caused very heterogeneous imbalances in world economies which may have important consequences for global instability and development. For example, the fact that developing economies have more asymmetric relationships with other developing countries implies that they might face higher volatility shocks. Furthermore, developed economies are more connected but their relations are on average more symmetric and, therefore, they have more control of volatility shocks. However, they are also connected to catching up economies which turn out to drive an important extent of the asymmetries of the world trade. This represents, presumably, a re-organization of the world trade core.

\section{References}

Anderson, J. E. and E. van Wincoop (2003). Gravity with gravitas: A solution to the border puzzle. American Economic Review 93(1), 170-192.

Baldwin, R. and D. Taglioni (2006). Gravity for dummies and dummies for gravity equations. NBER Working Papers 12516, National Bureau of Economic Research, Inc.

Barigozzi, M., G. Fagiolo, and D. Garlaschelli (2010, Apr). Multinetwork of international trade: A commodity-specific analysis. Physical Review E 81(4), 046104.

Bergstrand, J. H. (1985). The gravity equation in international trade: Some microeconomic foundations and empirical evidence. The Review of Economics and Statistics 67(3), 474-81.

Bergstrand, J. H., P. Egger, and M. Larch (2013). Gravity redux: Estimation of gravityequation coefficients, elasticities of substitution, and general equilibrium comparative statics under asymmetric bilateral trade costs. Journal of International Economics 89(1), 110-121.

Bernanke, B. S. (2005, April). The global saving glut and the U.S. current account deficit. Sandridge Lecture, Virginia Association of Economists, Richmond, Virginia. At: http://www.federalreserve.gov/boarddocs/speeches/2005/200503102/ [accesed on: February 2013]. 
Bhattacharya, K., G. Mukherjee, and S. Manna (2007). The international trade network. In A. Chatterjee and B. Chakrabarti (Eds.), Econophysics of Markets and Business Networks. Springer-Verlag, Milan, Italy.

Bhattacharya, K., G. Mukherjee, J. Sarämaki, K. Kaski, and S. Manna (2008). The international trade network: Weighted network analysis and modeling. Journal of Statistical Mechanics: Theory Exp. A 2, P02002.

Bracke, T., M. Bussire, M. Fidora, and R. Straub (2008, January). A framework for assessing global imbalances. Occasional Paper Series 78, European Central Bank.

Chung, F. and L. Lu (2002). Connected components in random graphs with given expected degree sequences. Annals of combinatorics 6(2), 125-145.

Colizza, V., A. Flammini, M. A. Serrano, and A. Vespignani (2006). Detecting rich-club ordering in complex networks. Nat. Phys. 2, 110-115.

Davis, D. R. and D. E. Weinstein (2002, May). The mystery of the excess trade (balances). American Economic Review 92(2), 170-174.

De Benedictis, L. and L. Tajoli (2011, August). The world trade network. The World Economy 34 (8), 1417-1454.

DeMontis, A., M. Barthélemy, A. Chessa, and A. Vespignani (2005). The structure and evolution of inter-urban traffic: A weighted network analysis. Environment And Planning B - Planning and Design 34, 905-924.

Dueñas, M. and G. Fagiolo (2013). Modeling the international-trade network: a gravity approach. Journal of Economic Interaction and Coordination 8(1), 155-178.

Fagiolo, G. (2007). Clustering in complex directed networks. Physical Review E 76, 026107.

Fagiolo, G. (2010). The international-trade network: gravity equations and topological properties. Journal of Economic Interaction and Coordination 5, 1-25.

Fagiolo, G., J. Reyes, and S. Schiavo (2010). The evolution of the world trade web: a weightednetwork analysis. Journal of Evolutionary Economics 20, 479-514. 10.1007/s00191-0090160-x.

Fagiolo, G., S. Schiavo, and J. Reyes (2008). On the topological properties of the world trade web: A weighted network analysis. Physica A 38\%, 3868-3873.

Fagiolo, G., S. Schiavo, and J. Reyes (2009). World-trade web: Topological properties, dynamics, and evolution. Physical Review E 79, 036115. 
Fagiolo, G., T. Squartini, and D. Garlaschelli (2012). Null models of economic networks: the case of the world trade web. Journal of Economic Interaction and Coordination, 1-33.

Feenstra, R. C. (2004). Advanced international trade: theory and evidence. Princeton University Press.

Gagnon, J. E. and A. K. Rose (1995). Dynamic persistence of industry trade balances: how pervasive is the product cycle? Oxford Economic Papers, 229-248.

Garlaschelli, D., T. Di Matteo, T. Aste, G. Caldarelli, and M. Loffredo (2007). Interplay between topology and dynamics in the world trade web. The European Physical Journal B 5\%, 1434-6028.

Garlaschelli, D. and M. Loffredo (2004). Fitness-dependent topological properties of the world trade web. Physical Review Letters 93, 188701.

Garlaschelli, D. and M. Loffredo (2005). Structure and evolution of the world trade network. Physica A 355, 138-44.

Hufbauer, G. C., Y. Wong, and K. Sheth (2006, 1st quart). U.S.-China Trade Disputes: Rising Tides Rising Stakes. Number pa78 in Peterson Institute Press: All Books. Peterson Institute for International Economics.

Krugman, P., M. Obstfeld, and M. Melitz (2011, January). International Economics: Theory and Policy (9th ed.). Prentice Hall.

Krugman, P. R. and R. Baldwin (1987). The persistence of the U.S. trade deficit. Brookings Papers on Economic Activity 18(1), 1-56.

Li, X., Y. Y. Jin, and G. Chen (2003). Complexity and synchronization of the world trade web. Physica A: Statistical Mechanics and its Applications 328, 287-96.

Marchetti, J., M. Ruta, and R. Teh (2012). Trade imbalances and multilateral trade cooperation. CESifo Working Paper Series 4050, CESifo Group Munich.

Maslov, S. and K. Sneppen (2002). Specificity and stability in topology of protein networks. Science 296(5569), 910-913.

Mattoo, A. and A. Subramanian (2008). Currency undervaluation and sovereign wealth funds: a new role for the world trade organization. Policy Research Working Paper Series 4668, The World Bank.

Molloy, M. and B. Reed (1995). A critical point for random graphs with a given degree sequence. Random Structures 85 Algorithms 6(2-3), 161-180. 
Newman, M. (2003). The structure and function of complex networks. SIAM review $45(2)$, $167-256$.

Opsahl, T., V. Colizza, P. Panzarasa, and J. J. Ramasco (2008, Oct). Prominence and control: The weighted rich-club effect. Phys. Rev. Lett. 101, 168702.

Reyes, J., S. Schiavo, and G. Fagiolo (2008). Assessing the evolution of international economic integration using random-walk betweenness centrality: The cases of East Asia and Latin America. Advances in Complex Systems 11, 685-702.

Roberts, E. S. and A. C. C. Coolen (2012, Apr). Unbiased degree-preserving randomization of directed binary networks. Phys. Rev. E 85, 046103.

Santos Silva, J. M. C. and S. Tenreyro (2006). The log of gravity. The Review of Economics and Statistics 88(4), 641-658.

Schweitzer, F., G. Fagiolo, D. Sornette, F. Vega-Redondo, A. Vespignani, and D. R. White (2009, JUL 24). Economic Networks: The New Challenges. SCIENCE 325(5939), 422-425.

Serrano, A. and M. Boguñá (2003). Topology of the world trade web. Physical Review E 68, 015101(R).

Serrano, A., M. Boguñá, and A. Vespignani (2007). Patterns of dominant flows in the world trade web. Journal of Economic Interaction and Coordination 2, 111-124.

Squartini, T., G. Fagiolo, and D. Garlaschelli (2011a, Oct). Randomizing world trade. i. a binary network analysis. Phys. Rev. E 84, 046117.

Squartini, T., G. Fagiolo, and D. Garlaschelli (2011b, Oct). Randomizing world trade. ii. a weighted network analysis. Phys. Rev. E 84, 046118.

Subramanian, A. and S.-J. Wei (2007). The WTO promotes trade, strongly but unevenly. Journal of International Economics 72(1), 151 - 175. 


\section{A List of Countries}

See Table 3.

Table 3: List of countries in the balanced panel.

\begin{tabular}{|c|c|c|c|c|c|}
\hline ISO & Country & ISO & Country & ISO & Country \\
\hline USA & United States & HTI & Haiti & CMR & Cameroon \\
\hline GBR & United Kingdom & HND & Honduras & $\mathrm{CAF}$ & Central African Rep. \\
\hline $\mathrm{AUT}$ & Austria & MEX & Mexico & TCD & Chad \\
\hline DNK & Denmark & NIC & Nicaragua & $\mathrm{COG}$ & Congo, Rep. of \\
\hline FRA & France & PAN & Panama & BEN & Benin \\
\hline GER & Germany & PRY & Paraguay & ETH & Ethiopia \\
\hline ITA & Italy & PER & Peru & GAB & Gabon \\
\hline NLD & Netherlands & URY & Uruguay & GMB & Gambia, The \\
\hline NOR & Norway & VEN & Venezuela, Rep. Bol. & GHA & Ghana \\
\hline SWE & Sweden & BHS & Bahamas, The & GNB & Guinea-Bissau \\
\hline CHE & Switzerland & BRB & Barbados & GIN & Guinea \\
\hline CAN & Canada & GUY & Guyana & CIV & Cte d'Ivoire \\
\hline JPN & Japan & BLZ & Belize & KEN & Kenya \\
\hline FIN & Finland & JAM & Jamaica & MDG & Madagascar \\
\hline GRC & Greece & SUR & Suriname & MLI & Mali \\
\hline ISL & Iceland & TTO & Trinidad and Tobago & MRT & Mauritania \\
\hline IRL & Ireland & CYP & Cyprus & MUS & Mauritius \\
\hline PRT & Portugal & IRN & Iran, I.R. of & MAR & Morocco \\
\hline ESP & Spain & ISR & Israel & $\mathrm{MOZ}$ & Mozambique \\
\hline TUR & Turkey & JOR & Jordan & NER & Niger \\
\hline AUS & Australia & SAU & Saudi Arabia & NGA & Nigeria \\
\hline NZL & New Zealand & SYR & Syrian Arab Rep. & SEN & Senegal \\
\hline $\mathrm{ZAF}$ & South Africa & EGY & Egypt & SLE & Sierra Leone \\
\hline $\mathrm{ARG}$ & Argentina & LKA & Sri Lanka & TGO & Togo \\
\hline BOL & Bolivia & HKG & Hong Kong & TUN & Tunisia \\
\hline BRA & Brazil & IND & India & UGA & Uganda \\
\hline CHL & Chile & IDN & Indonesia & BFA & Burkina Faso \\
\hline COL & Colombia & KOR & Korea & FJI & Fiji \\
\hline CRI & Costa Rica & PAK & Pakistan & PNG & Papua New Guinea \\
\hline DOM & Dominican Rep. & PHL & Philippines & $\mathrm{CHN}$ & $\begin{array}{l}\text { China,P.R.: Main- } \\
\text { land }\end{array}$ \\
\hline $\mathrm{ECU}$ & Ecuador & THA & Thailand & HUN & Hungary \\
\hline SLV & El Salvador & DZA & Algeria & $\mathrm{ROM}$ & Romania \\
\hline GTM & Guatemala & AGO & Angola & & \\
\hline
\end{tabular}




\section{B List of Variables}

\section{See Table 4.}

Table 4: List of link- or country-related variables employed in gravity estimation exercises.

\begin{tabular}{|c|c|c|c|}
\hline Label & Related to & Description & Source \\
\hline$W$ & Link & Imports in U.S. Dollars & Subramanian and Wei (2007) \\
\hline Y & Country & Gross-domestic product & Subramanian and Wei (2007) \\
\hline area & Country & Country area in $\mathrm{Km}^{2}$ & Subramanian and Wei (2007) \\
\hline pop & Country & Country population & Subramanian and Wei (2007) \\
\hline$d$ & Link & $\begin{array}{l}\text { Distance between two coun- } \\
\text { tries, based on bilateral dis- } \\
\text { tances between the largest } \\
\text { cities of those two countries, } \\
\text { weighted by the share of the } \\
\text { city in the overall country's } \\
\text { population }\end{array}$ & CEPII (http://www.cepii.fr/) \\
\hline landl & Country & $\begin{array}{l}\text { Dummy variable equal to } 1 \text { for } \\
\text { landlocked Countries }\end{array}$ & CEPII (http://www.cepii.fr/) \\
\hline continent & Country & $\begin{array}{l}\text { Categorical variable indicating } \\
\text { the continent of the country }\end{array}$ & CEPII (http://www.cepii.fr/) \\
\hline contig & Link & $\begin{array}{l}\text { Contiguity dummy equal to } 1 \text { if } \\
\text { two countries share a common } \\
\text { border }\end{array}$ & CEPII (http://www.cepii.fr/) \\
\hline comlang_off & Link & $\begin{array}{l}\text { Dummy equal to } 1 \text { if both coun- } \\
\text { tries share a common official } \\
\text { language }\end{array}$ & CEPII (http://www.cepii.fr/) \\
\hline comcol & Link & $\begin{array}{l}\text { Dummy equal to } 1 \text { if both coun- } \\
\text { tries have had a common colo- } \\
\text { nizer }\end{array}$ & CEPII (http://www.cepii.fr/) \\
\hline colony & Link & $\begin{array}{l}\text { Dummy equal to } 1 \text { if both coun- } \\
\text { tries have ever had a colonial } \\
\text { link }\end{array}$ & CEPII (http://www.cepii.fr/) \\
\hline comrelig & Link & $\begin{array}{l}\text { Percentage in which both coun- } \\
\text { tries share religions }\end{array}$ & CEPII (http://www.cepii.fr/) \\
\hline comcur & Link & $\begin{array}{l}\text { Dummy equal to } 1 \text { if both coun- } \\
\text { tries have a currency unions }\end{array}$ & CEPII (http://www.cepii.fr/) \\
\hline rta & Link & $\begin{array}{l}\text { Dummy variable equal to } 1 \text { if } \\
\text { both countries involved in re- } \\
\text { gional, bilateral or preferential } \\
\text { trade agreements }\end{array}$ & WTO (http://www.wto.org/) \\
\hline
\end{tabular}

